10-1-1994

\title{
Implementation and Impact of the Patient Self-Determination Act
}

Denise C. Park

University of Georgia Dept. of Psychology

Thomas A. Eaton

University of Georgia School of Law, teaton@uga.edu

Edward J. Larson

University of Georgia School of Law

Helen T. Palmer

University of Georgia Dept. of Psychology

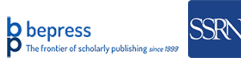

\section{Repository Citation}

Denise C. Park, Thomas A. Eaton, Edward J. Larson, and Helen T. Palmer, Implementation and Impact of the Patient Self-Determination Act (1994),

Available at: https://digitalcommons.law.uga.edu/fac_artchop/506

This Article is brought to you for free and open access by the Faculty Scholarship at Digital Commons @ University of Georgia School of Law. It has been accepted for inclusion in Scholarly Works by an authorized administrator of Digital Commons @ University of Georgia School of Law. Please share how you have benefited from this access For more information, please contact tstriepe@uga.edu. 


\title{
Implementation and Impact of the Patient Self-Determination Act*
}

DENISE C. PARK, PhD, THOMAS A. EATON, JD, EDWARD J. LARSON, JD, PhD, and HELEN T. PALMER, PhD, Athens, Ga

\begin{abstract}
The Patient Self-Determination Act became effective in December 1991 and mandates that patients be given information about legal rights regarding living wills and durable powers of attorney for health care. We investigated the impact this law has had on hospitals, medical personnel, and patients. We conducted a survey of all hospitals in the state of Georgia, collecting data regarding implementation and knowledge of the law, as well as effects of the law and beliefs about it. The data indicated that hospitals relied primarily on the Georgia Hospital Association for implementation policy, that

"minimalist" implementation of the law occurs in most hospitals, and that the biggest perceived problem with the law was the inappropriateness of presenting this information at hospital admission and problems patients had in comprehending the materials presented. Despite these concerns, most respondents did not want the law repealed.
\end{abstract}

ThE PATIENT Self-Determination Act (PSDA) ${ }^{1}$ was enacted in late 1990 and became effective a year later on December 1, 1991. The cornerstone of the PSDA is its requirement that health care facilities inform patients of their rights under state law to make decisions regarding medical care, including "the right to accept or refuse medical or surgical treatment and the right to formulate advance directives"' such as living wills and durable powers of attorney for health care (DPAHC). This mandate appears to follow in the tradition of the legal doctrine of informed consent, but there is a significant difference. The PSDA differs from informed consent doctrine in that it compels health care facilities to advise patients of their legal rights whereas informed consent required only the disclosure of medical information. This mandate applies to all health care facilities receiving Medicare or Medicaid funds, including hospitals, skilled nursing facilities, home health and personal care agencies, and health maintenance organizations. Never has there been a law that required health care faclities to advise patients of their legal rights on such a massive scale.

\section{BACKGROUND}

Several studies suggest a substantial gap between the number of adults who say they would like to have an advance directive and those who

*Presented belore the Annual Meeting of the American Bar Associ. ation, New York, August 3-11, 1993.

From the Department of Psychology and the School of Law, University of Georgia, Athens.

Reprint requests to Denise $\mathrm{C}$. Park, PhD, Department of Psychol ogy, University of Ceorgia, Athens, GA 30602 have actually signed such a document. ${ }^{2 \cdot 5}$ The PSDA is intended to reduce this gap through education..$^{6-8}$ An underlying premise of the legislation is that if people are informed about advance directives, they are more likely to execute such documents. Greater use of advance directives, in turn, will help avoid the difficult ethical and legal issues presented in "right to die" cases, such as the Nancy Cruzan ${ }^{9}$ case, in which the patient had not clearly expressed her treatment preferences.

The actual impact of this statute on patient behavior, however, will largely be determined by how it is implemented by health care providers. Several observers have expressed concern that health care facilities will succumb to the temptation of achieving "paper compliance" with the PSDA instead of striving to provide meaningful communication with patients. ${ }^{3,6.8,10.11}$ The fear is that the PSDA might produce a bureaucratic ritual instead of an interactive face-to-face dialogue that enhances patient decision making. Thus, the primary purpose of the present project was to determine what procedures are being used in hospitals to implement the PSDA and the perceived effect of these procedures on staff and patients.

Despite the recognition of the importance of implementation of the PSDA, little is known about what institutions are actually doing. The few reports available are limited to the activities of individual institutions. ${ }^{1113}$ We undertook a statewide survey of hospitals in Georgia to ascertain on a broad scale how the PSDA is being implemented. Only hospitals in Georgia were 


\begin{tabular}{|c|c|c|}
\hline \multirow[b]{2}{*}{ Question (Anstert) } & \multicolumn{2}{|c|}{ Haspials } \\
\hline & $\begin{array}{l}\text { Large } \\
n=41\end{array}$ & $\begin{array}{l}\text { Small } \\
n=40\end{array}$ \\
\hline $\begin{array}{l}\text { Only Medicare/Medicaid patients must be informed of rights to execute advance directives/refuste treat } \\
\text { ment. (False) }\end{array}$ & 902 & .875 \\
\hline Written materials explaining rights must be provided to patients. (True) & .878 & 975 \\
\hline Patient's decision not to execute advance directive need not be noted in medical record. (False) & 78 & .825 \\
\hline Living will may authorize removal of feeding tubes from vegetative patients. (True) & 927 & $.70^{*}$ \\
\hline Durable power of attorney may authorize the removal of feeding tubes trom vegetative patients. (True) & 951 & 90 \\
\hline $\begin{array}{l}\text { Living will may authorize withholding/withdrawing antibiotics for incurable, but not immediately life- } \\
\text { threatening disease. (False) }\end{array}$ & .878 & $.575 \%$ \\
\hline $\begin{array}{l}\text { Durable power of attorney may authorize witholding/withdrawing antibiotus for incurable, but not } \\
\text { immediately life-threatening. disease. (True) }\end{array}$ & .738 & .525 \\
\hline $\begin{array}{l}\text { Under durable power of attorney, agent may be instructed to not consent to removal of feeding tubes. } \\
\text { (True) }\end{array}$ & .951 & .95 \\
\hline $\begin{array}{l}\text { Under durable power of attorney, agent may order withdrawal/witholding of treatment only when patient } \\
\text { is in terminal condition. (False) }\end{array}$ & .780 & $.45+$ \\
\hline Living will executed in a hospital must be witnessed by patient's attending physician. (False) & 902 & .775 \\
\hline $\begin{array}{l}\text { Durable power of attorney executed in a hospital must be witnessed by patient's attending physician. } \\
\text { (True) }\end{array}$ & .732 & $.475^{*}$ \\
\hline Tifcant at 05 . & & \\
\hline
\end{tabular}

investigated because laws pertaining to advance directives vary significantly from state to state. ${ }^{14}$ Consequently, information distributed pursuant to the PSDA will vary from state to state. The goals of the legislation and the concerns expressed about its implementation dictated the issues that we investigated. The issues addressed were as follows.

\section{Development of Awareness of the Law and the Information-Gathering Process}

We assessed how hospitals became aware of the PSDA and how they formulated policy designed to comply with the legislation. Specifically, we sought to determine the extent to which hospitals relied on professional organizations to formulate implementation policy and the extent to which such policy was formulated at the institutional level.

\section{Implementation and Compliance With the Law}

Recognizing that the standardized disclosure of information in the hospital setting might not produce meaningful communication, we assessed the type of information actually presented to patients under the PSDA and the mechanisms in place for assuring patient comprehension of the material presented.

\section{Knowledge of the Law}

We asked several questions designed to ascertain whether hospital personnel accurately understood the PSDA and state law regarding advance directives. This is obviously critical for proper implementation of the law, especially because statutes authorizing advance directives and court decisions regarding the right to refuse unwanted medical treatment can be quite complex and vary dramatically from state to state. ${ }^{14}$

\section{Effects of the Law}

The PSDA is based on the premise that informing patients of their rights will lead to an increased use of advance directives. ${ }^{6-8}$ Yet, some studies question this connection. ${ }^{15 \cdot 17}$ Although most hospitals do not keep formal records, we assessed perceptions of hospital personnel regarding any increase in the percentage of patients completing advance directives subsequent to the enactment of the PSDA.

\section{Attitudes Toward the Law}

The attitude of persons charged with the respon sibility of implementing a law can have a signifi cant impact on how that law is put into effect Therefore, we identified the persons who interact with patients and measured the perceived atti tude of various categories of hospital personne! toward the PSDA.

\section{SUBJECTS AND METHODS}

Subjects

Every administrator of a hospital in the state of Georgia $(N=210)$ received a survey. A total of 102 surveys were retumed, for a completion rate of $49 \%$. Upon receipt of the surveys, it was noted that 13 of the hospitals from which a response was received were primarily psychiatric or acute care. These surveys were discarded and only the results 
TABLE 2. Perceived Attitude of Hospital Staff and Patients Toward the Patient Self-Determination Act (PSDA) as a Function of Hospital Size

\begin{tabular}{|c|c|c|c|}
\hline Staff Colagny & $\begin{array}{l}\text { Latge } \\
(n=+1)\end{array}$ & $\begin{array}{l}\text { Swall } \\
(n=4)\end{array}$ & Meck \\
\hline $\begin{array}{l}\text { Aminismaturs } \\
\text { (Shandatd devidion) }\end{array}$ & $\begin{array}{l}2.43 \\
(1.19)\end{array}$ & $\begin{array}{l}2.19 \\
(1.05)\end{array}$ & $\begin{array}{l}2.32 \\
(1.07)\end{array}$ \\
\hline $\begin{array}{l}\text { Nursing Statt } \\
\text { (Srandird devation) }\end{array}$ & $\begin{array}{l}2.5 \\
(1.52)\end{array}$ & $\begin{array}{l}2.54 \\
(0.99)\end{array}$ & $\begin{array}{l}2.53 \\
(0.996)\end{array}$ \\
\hline $\begin{array}{l}\text { Physicians } \\
\text { (Standurd devation) }\end{array}$ & $\begin{array}{c}2.64 \\
(1,96\}\end{array}$ & $\begin{array}{l}2.58 \\
(1.166)\end{array}$ & $\begin{array}{l}2.6 \\
(1.01)\end{array}$ \\
\hline $\begin{array}{l}\text { Subial Services Stan } \\
\text { (Standart deviaton) }\end{array}$ & $\begin{array}{l}2.63 \\
(1) .94)\end{array}$ & $\begin{array}{l}2.33 \\
(1.15)\end{array}$ & $\begin{array}{l}2.13 \\
(1.04)\end{array}$ \\
\hline $\begin{array}{l}\text { Pationts } \\
\text { (Standard deviation) }\end{array}$ & $\begin{array}{l}2.6 \\
(1) .80)\end{array}$ & $\begin{array}{l}2.97 \\
(1.01)\end{array}$ & $\begin{array}{r}2.78 \\
(0.93)\end{array}$ \\
\hline $\begin{array}{l}\text { Mean } \\
\text { (Standard deviation) }\end{array}$ & $\begin{array}{l}2.44 \\
(0.98)\end{array}$ & $\begin{array}{l}2.51 \\
(1.68)\end{array}$ & \\
\hline 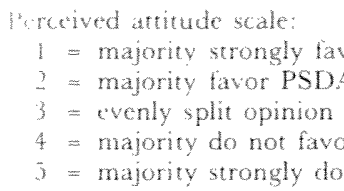 & $\begin{array}{l}\text { PSDA. } \\
\text { Ut PSDA. } \\
\text { SDA. } \\
\text { favor PS }\end{array}$ & 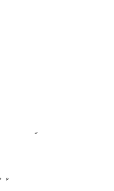 & \\
\hline
\end{tabular}

of the remaining 81 general medical hospitals are presented here. The administrator who received the survey was encouraged to delegate the task of completing the survey to the most appropriate person, so a variety of people completed the instrument. The primary job categories of the persons completing the survey were organizational or management, with $27 \%$ of the respondents designated as risk managers for the hospital and $53 \%$ managing specific departments (Admissions, Social Services, etc) or serving as vice president or chief executive officer. Sixteen percent were best categorized as "other" (such as assistant administrator or legal services officer). Four percent did not answer this item. The respondents represented hospitals with the following characteristics: the mean bed size was 175.53 (range of 21 to 1,200 beds, SD $=202.85$ ), with 22 located in metropolitan statistical areas (categorized as urban), whereas the remainder were located in nonmetropolitan statistical areas (categorized as rural). A total of $48 \%$ of the hospitals were owned by a nonprofit hospital authority, and an additional $26 \%$ were lescribed as nongovernmental/not for profit. Ten percent were for profit/investor owned, $9 \%$ were wned by a local government, and the remainder were "other" or the item was not completed.

The hospitals that responded were divided into two comparison categories: large versus small and urban versus rural. The large/small categorization was developed by means of a median split in terms of bed size. Large hospitals are those with more than 84 beds, small hospitals are those with 84 beds or less. The median split procedure resulted in 40 hospitals being categorized as small and 41 as large. Differences reported for large versus small hospitals are based on this categorization. In addition, a subset of hospitals was categorized as urban/rural and matched for bed size. Of the 81 general medical hospitals represented in the survey results, 22 were located in metropolitan statistical area (MSAs) and 59 were in non-MSA or rural areas. The largest urban hospital has 1,200 beds, 598 more than the next largest one. This hospital was considered an outlier and dropped from further analyses, resulting in a group of 21 urban hospitals. A subset of 21 rural hospitals was selected that most closely matched the urban hospitals for bed size. The match procedure resulted in a mean bed size of 253.62 ( $\mathrm{sd}=201.36$ ) for urban hospitals and a mean bed size for rural hospitals of $243.29(\mathrm{sd}=187.7)$.

\section{Methods}

The survey instrument consisted of 60 questions that were printed in a booklet and mailed to hospital administrators by the University of Georgia Survey Research Center. Follow-up phone calls were made for those not completing the survey. The surveys were mailed on October 2, 1992, 10 months after the PSDA took effect. All surveys were completed by December 15, 1992. All but 17 of the questions were forced choice, with the others being open-ended short answer questions (eg, "What is your specific job title?') The survey was divided into five major sections that assessed different aspects of the PSDA. As noted earlier, these sections addressed major concerns: (a) hospital personnel's development of awareness and information-gathering procedures, (b) the hospital's present procedures for implementing the law, (c) the individual respondent's personal knowledge and interpretation of the law, (d) the perceived effect of the PSDA with respect to completion of advance directives, and (e) hospital personnel's attitudes and opinions about the law.

\section{RESULTS AND COMMENTS}

Development of Awareness of the Law and the Information-Gathering Process

The PSDA was passed on November 5, 1990, with the requirement that it be implemented by December 1, 1992. Hospitals typically responded slowly to this mandate. When asked when hospital officials first learned about the legal responsibilities under the law, only $9 \%$ reported knowing about them within 1 month after passage and an additional $7 \%$ reported learning of them within 3 months after passage. Another 23\% learned of the responsibilities by June 1991 ( 6 months after passage), $19 \%$ more by September 1991 ( 9 months), and a full $23 \%$ learned of them only 2 
months prior to the required implementation. The remaining $20 \%$ of the respondents did not know or did not answer this question. Overall, the data suggest that knowledge of the hospital's responsibilities was not high until the few months prior to the law's implementation.

Further, a third of the responding hospital officials indicated that their hospitals took their first formal steps to develop a plant for compliance with the PSDA between July and September 1991, with the December implementation date rapidly approaching, while another third first acted between October and December 1991. These data reflect a significant lag time between the enactment of legislation and hospital awareness and response.

The results indicate that the primary mechanism for developing awareness of the law was through the Georgia Hospital Association (44\%), followed by multiple sources $(17 \%)$, which could include the Georgia Hospital Association. There were no differences in awareness between large and small or urban and rural hospitals. When asked specifically how hospital personnel learned of the hospital's legal responsibilities under the law (and to respond to as many of the 12 categories that applied), 80\% reported gaining this information from the Georgia Hospital Association; only $19 \%$ indicated information was provided by a hospital attorney. Thirty-two percent examined the actual legislation and $33 \%$ indicated awareness developed from multiple sources over time. No other category received a response rate of $15 \%$ or greater. Large hospitals were more likely to secure information from their attorney compared to small $(16 \%$ vs $3 \%)\left(\mathrm{X}^{2}=9.571, P=.002\right)$ but no other differences were significant.

With respect to lobbying activities associated with the law, $36 \%$ of the respondents indicated that hospital personnel were definitely aware of the possibility of legislation on advance directives prior to the law's passage, and only $15 \%$ believed hospital personnel were unaware of the possibility of legislation. Nevertheless, the respondents were not aware of efforts made on the part of hospital officials to influence the passage of the legislation, as only $3.7 \%$ indicated such activities occurred, with $77.8 \%$ stating that no attempts were made, and $18.5 \%$ did not know if attempts were made.

To summarize, the data indicated that the primary source of information regarding the PSDA was the Georgia Hospital Association, and that there was only moderate awareness of the law prior to its passage on the parts of hospitals. Moreover, little attempt was made by hospital representatives to influence the outcome of the pending legislation.

A series of questions addressed the structural/ organizational procedures the hospital used to formulate a plan for complying with the law after it was passed. The data confirm the prevailing belief that professional organizations play a dominant role in shaping institutional responses to a new law. ${ }^{18.19}$ When asked for the three most influential procedures in developing a compliance plan, 3 items from the 11 alternatives presented were most likely to be ranked first. Thirty-three percent chose "awaiting word from the Georgia Hospital Association," whereas another 33\% reported that forming an in-house committee was the primary alternative for dealing with the law. Seventeen percent reported the primary procedure was to delegate planning responsibilities to a single individual.

When asked what single source of information was most influential in developing a plan, the Georgia Hospital Association was overwhelmingly selected first by the respondents (64\%) from the 18 choices provided. Another $12 \%$ indicated that they relied on a committee of health care providers as their first source, and $6 \%$ reported relying on materials prepared by for-profit commercial enterprises. Larger hospitals were more likely to utilize multiple sources of information, including attorneys, than were smaller hospitals. Smaller hospitals tended to rely more completely on professional associations for advice and direction. Regardless of hospital size, however, the dominant source of procedural information about how to implement PSDA was provided by the State Hospital Association.

\section{Implementation and Compliance with the Law}

The results of the survey indicate that most hospitals comply with the PSDA by providing patients with a written explanation of state law regarding advance directives, but that little effort is made to initiate a discussion about the material. Ninety-six percent of the respondents reported that all of their patients receive written explanations of relevant state law as required by the PSDA. These written explanations were prepared by the hospital itself ( $54 \%$ ), the Georgia Hospital Association $(24 \%)$, the state $(3 \%)$, or by a source that was not ascertained (10\%). Twenty-five percent of the hospitals present all patients with forms for a living will and $27 \%$ with forms for durable power of attorney for health care (DPAHC), even though this is not required by the PSDA. Thirty. two percent of the hospitals distribute a glossary of terms with their materials. Only one-third of

ex]

rot

ex]

the

ast

rec

for

af

vic

in

prr

ing

me

ful

int

sic

ve

wl

pr

cle

op

su

se:

all

$\mathrm{m}$

sh

$\operatorname{tr}_{i}$

th

te 1

(1:

th

ev

so

st1

re:

fo:

be

ar

in

CC

W

A

th 
1ral/

for-

after

ling

om-

to a

nost

ance

ated

hree

rgia

$33 \%$

was

law.

dure

sin-

tion

the

ngly

the

that

ders

; on

iter-

uti-

ling

aller

sro-

ion.

lant

$\checkmark$ to

tate

.ost

ling

law

fort

cial.

that

ons

JA.

the

oci-

hat

ent

for

ible

ven

rty"

ary

ird of the respondents routinely provide a verbal explanation of advance directives. Another $10 \%$ routinely provide their patients with a video that explains advance directives.

Seventy percent of the hospitals surveyed offer the patient an opportunity to ask questions. When asked what was available to a patient only if requested, the responses were as follows: forms for a living will (70\%), forms for DPAHC (69\%), a further verbal explanation of the law $(40 \%)$, a video $(20 \%)$, and a glossary of terms and meanings (14\%). Only a small fraction (5\%) routinely provide follow-up counseling for patients requesting advance directives even though many commentators and proponents view this to be vital to fulfill the law's objectives. ${ }^{3,6,10,20}$

The most common time for patients to receive information about advance directives is at admission $(83 \%)$, and the information is typically conveyed by the admissions staff $(83 \%)$. The places where patients receive this information are in a private office or room (43\%), an admissions cubicle $(27 \%)$, in the patient's room $(15 \%)$, or in an open area of the hospital (9\%). Any follow-up consultation is usually provided by the hospital's social service staff $(48 \%)$ or the nursing staff $(15 \%)$, and almost never by doctors (1\%), even though commentators have stressed their belief that physicians should provide such consultation. ${ }^{3,6,10,16,20}$ Staff training about the PSDA is typically provided through in-house presentations (68\%) and written materials (48\%), or is not provided at all $(12 \%)$. Most patients are presumed to understand the information (mean $=74.03 \%, \mathrm{sd}=20.32$ ), even though it has been questioned whether persons can comprehend this information at the stressful time of hospital admission..$^{3,11}$ Most respondents indicate that no formal procedures are followed to determine if these patients understand, beyond asking them if they understand or have any questions. Respondents from large hospitals indicated that $79.88 \%$ of patients were judged competent to receive information about the law, whereas small hospitals reported a rate of $68.17 \%$. Analysis using Student's one-tailed $t$ test indicated this was a significant difference $(t(1,69)=2.5$, $P=.015)$.

In light of these findings regarding minimalist implementation of the PSDA, it is not surprising that nearly all $(90 \%)$ of the respondents reported that the length of time taken to explain the information to each patient was 10 minutes or less, with $43 \%$ reporting that less than 5 minutes was taken. Only $7 \%$ reported taking more than 10 minutes for this task. Pre-implementation studies suggested that conveying this information would take at least
15 minutes. ${ }^{2}$ The relatively brief time spent with patients is consistent with the view of most hospitals that their role is to inform patients about their rights to execute advance directives ( $52 \%$ ), rather than to educate patients on this subject (25\%), or encourage the execution of advance directives $(6 \%)$. Certainly the PSDA does not suggest that hospitals should compel patients to execute such directives and affirmatively prohibits discriminating against patients who do not do so, but the Act specifically directs hospitals to "educate" people about advance directives. Proponents clearly hoped to encourage greater utilization of advance directives. In their implementation of the PSDA, respondents are reluctant to go beyond the minimal mandate of the law.

\section{Knowledge of the Law}

A series of 11 items assessed the respondent's knowledge of the law. The questions and proportion of correct answers for each item appear in Table 1 . The mean total number correct was 8.95 ( $\mathrm{sd}=1.86$ ). The poorest performance, overall, was on questions regarding noting patient desires in medical records and witnessing by a physician, the withdrawal of antibiotics in not immediately lifethreatening conditions, and the conditions under which an agent may order treatment to be withheld. Respondents from large hospitals and higher scores with a mean of $9.41(\mathrm{sd}=1.46)$ correct, whereas respondents from small hospitals had a mean of $8.02(\mathrm{sd}=1.86)$, a significant difference, $\mathrm{t}(1,80)=3.73, P=.0004$. The overall significant difference was a function of differences on four questions from the battery, as shown in Table 1. This may be explained by the fact that larger hospitals drew upon multiple sources of information and more frequently involved attorneys than did smaller hospitals in implementing the PSDA. There was no difference between urban and rural hospitals.

A premise of the PSDA was that health care facilities could provide patients with accurate information about legal rights. Our data identify some areas of concern in that regard. The PSDA requires documentation in the patient's medical record whether or not the patient has executed an advance directive. Nineteen percent of our respondents believed that such notation was not required when an advance directive had not yet been executed. The PSDA expressly requires that the information given to patients include rights "recognized by the courts of the State," yet only $40 \%$ of the hospitals indicated that they explain the right to refuse treatment recognized by judicial decisions. The information given patients by 
the hospitals deals almost exclusively with statutory living wills and durable power of attorney for health care (DPAHC) rather than common law or constitutional rights. Yet there was even widespread misunderstanding about the reach of living wills and DPAHC. For example, $36 \%$ of the respondents incorrectly believed that an agent under DPAHC could authorize the withdrawal of life-sustaining treatment only when the patient is in a terminal condition.

\section{Perceived Results of the Law}

Only $19 \%$ of respondents reported that their hospital kept records regarding the number or percentage of patients executing advance directives. Respondents estimated that prior to the passage of the PSDA, approximately $3.34 \%$ of patients had advance directives in effect during hospital stays, whereas they estimated that the number increased to $12.24 \%$ after the passage of the act. Proponents of the PSDA justified the law with survey evidence suggesting that most people wanted advance directives but did not have them, ${ }^{3,11}$ presumably because of a lack of information about them that could be supplied by hospitals upon patient admission. Thus, the passage of the PSDA, which mandates the distribution of such information, should lead to the execution of advance directives by more patients. The survey does not provide evidence that this objective has been fulfilled. Even though the percentage of patients perceived by respondents to have advance directives increased from $3.34 \%$ to $12.24 \%$, the latter percentage is still small and the increase could come from other factors, such as increased awareness of advance directives not associated with PSDA. The significance of other factors is suggested by our findings that more patients completing advance directives do so prior to admission (40\%) than at any other time, which is before the information provided under the PSDA could have a direct effect. Nevertheless, it is likely that the passage of the PSDA has increased general public awareness about advance directives and its passage could have indirectly accounted for the higher estimates after passage of the act. The estimated number of patients actually completing advance directives during a hospital stay after receiving the information was only $5.79 \%$. Thus, the data suggest that despite passage of the law, the majority of patients do not complete advance directives.

\section{Attitudes and Beliefs About the Law}

The survey included individual items regarding the perceived attitudes of hospital administrators, nursing stafl, physicians, social services staff, and patients toward the "portion of the Patient
Self-Determination Act that requires informing patients of their rights to execute advance directives and their rights to refuse treatment." Responses were on a 5-point scale from "a majority strongly favor" to a "majority do not strongly favor." The results appear in Table 2 as a function of hospital size. A mixed analysis of variance (ANOVA) with hospital as a between-group variable and staff member type as a within-subject variable yielded only a significant effect of staff member type (f value $(4,184)=6.66, P<.0001$ ) . The social services staff was perceived to have a significantly more positive attitude toward the Act than the other groups. Patients were perceived to be the least positive and individual ANOVA comparisons indicated they were significantly different from every other group. It is important to note, however, that in general all categories of health care providers were perceived as supporting the basic tenets of the PSDA. Perceptions of "support" or "strongly support" outnumbered perceptions of "do not support" or "strongly do not support" by approximately 3 to 1 for administrative staff, nursing staff, and physicians. Seventy-two percent of the respondents perceived the social services staff to "support" or "strongly support" the PSDA. The strong perceived level of support of the social services staff may be important because the social services staff is most frequently responsible for directly responding to patient's inquiries about advance directives. A favorable view of the law by the group most directly involved with patients enhances the prospect of successful implementation. Although patients were perceived as least supportive, the overall direction of the responses for them was still positive.

When asked the three biggest problems with the law from a list of eight, $73 \%$ of respondents selected the inappropriateness of the time of hospital admission for discussing advance directives as one of the top three, and $74 \%$ selected the difficulty they had in presenting information of this complexity to patients. The next most frequent choice was the amount of time it took to inform patients about advance directives (38\%) and the belief that staff members were unqualified to present information about legal matters (38\%). The amount of time required to inform patients about advance directives was viewed as a problem by some $38 \%$ of respondents, although $89 \%$ of those reported that hospital personnel spent 10 minutes or less in this process. Only $16 \%$ reported that no problems had been encountered.

A major concern expressed about the PSDA was that patients would be distressed by being con-

fror thei hos pat rest that infe the

Tw ere rep adc der "st infe tre: pat shc pat cer of : ref ver no: Int rer $\mathrm{Or}$ the pe: (1) Ac dis otl rel so: pls dis gr or $\mathrm{ab}$ th 
Jrming direcnent." m "a

to not le 2 as of vargroup ubject f staff )001). ave a le Act red to comliffernt to es of portns of sered ly do minans. ived ngly evel porfre5 to

fronted with advance directives and the issue of their right to die at the already stressful time of hospital admission. ${ }^{3 \cdot 10.11}$ When asked about patients' response to receiving the information, respondents indicated that the biggest problem was that patients had trouble understanding the information $(41 \%)$, whereas only $14 \%$ indicated the most common reaction was one of distress. Twenty percent reported patients were not bothered by receiving this information and $11 \%$ reported patients to be thankful to get it. In two additional questions addressing this issue, respondents indicated that $15.74 \%$ of patients are "strongly distressed" when presented with the information and $11.09 \%$ are "moderately distressed.' In a follow-up study, we will survey patient responses on this point. Further studies should examine the impact of this distress on patient responses to treatment. Despite the concerns described, when asked what the overall level of administrative difficulties was with the Act, $40 \%$ reported minor inconvenience and $16 \%$ no inconvenience. Another 40\% reported significant but not serious inconvenience.

\section{Interest in Change to PSDA}

Most respondents did not want the PSDA repealed, despite some of the problems reported. Only $16 \%$ agreed $(9 \%)$ or strongly agreed $(7 \%)$ that they would like the Act repealed. Thirty-seven percent, however, agreed (27\%) or strongly agreed $(10 \%)$ that they would like to see changes in the Act. The main interest in change was to have the distribution occur in a physician's office or at some other location, such as when driver's licenses are renewed. This is not surprising given hospital personnel's overall support of the PSDA in principle, and their reservations about the timing of the disclosure. It should be noted, however, that Congress considered whether to make the physician or hospital responsible for informing patients about advance directives, and consciously chose the latter.?

Acknowledgments. This research was supported by a grant to the first three authors from the AARP Andrus Foundation.
Washington, DC. The authors thank Sarita Reddy and Melissa Zwahr for assistance with date scoring and analysis.

\section{References}

1. Omnibus Budget Reconciliation Act of 1990, P.L. 101-508, 4206 and 4751 , codified at 42 U.S.C. $\$ 1395 \mathrm{cc}$ (a) (1) (Q), 1395 $\mathrm{mm}(\mathrm{c})(8), 1395 \mathrm{cc}(\mathrm{f}), 1396 \mathrm{a}(57),(58), 1396 \mathrm{a}(\mathrm{w})$

2. Emanual LL, Barry MJ, Stoeckle JD, et al: Advance directives for medical care-a case for greater use. $N$ Engl J Med 1991; 324:889-895

3. Wolfe SM, Boyle P, Callahan D, et al: Sources of concern about the Patient Self-Determination Act. $N$ Engl J Med 1991; 236:1666-1671

4. Stelter KL, Elliott BA, Bruno CA: Living will completion in older adults. Arch Intern Med 1992; 152:954-959

5. Broadwell AW, Boisaubin EV, Dunn JK, et al: Advance directives on hospital admission: a survey of patient attitudes. Sotth Med J 1993; 86:165-168

6. McCloskey EL: The spirit of the PSDA. Hastings Center Report $1991 ; 21: S 14-\mathrm{S} 15$

7. Rouse F: Patients, providers, and the PSDA. Hastings Center Report 1991; 21:S2-S3

8. Lynn J, Teno JM: After the Patient Self-Determination Act: the need for empirical research on formal advance directives. Hastings Center Report 1993; 23:20-24

9. Cruzan v Director, Missouri Department of Health, 497 U.S. 261,110 S. Ct. 2841 (1990)

10. LaPuma J, Orentlicker D, Moss RJ: Advance directives on admission: clinical implications and analysis of the Patient SelfDetermination Act of 1990. JAMA 1991; 266:402-405

11. Cate FH, Gill BA: The Patient Self-Determination Act: implementation issues and opportunities. The Annenberg Washington Program 1991:1-25

12. Mezey M, Latimer B: The Patient Self-Determination Act: an early look at implementation. Hastings Center Report 1993; 23:16-20

13. Idemoto BK, Daly BJ, Eger DL, et al: Implementing the Patient Self-Determination Act. Am J Nursing 1993; 93:20-25

14. Eaton TA, Larson, EJ: Experimenting with the "right to die" in the laboratory of the States. Ga Law Review 1991; 25:1253-1326

15. Sachs GA, Stocking CE, Miles SH: Failure of an intervention to promote discussion of advance directives. J Am Geriatr Soc 1992; 40:269-273

16. Hare J, Nelson C: Will outpatients complete living wills? a comparison of two interventions. J Gen Intern Med 1991; 6:41-46

17. Sehgal A, Galbraith A, Chesney M, et al: How strictly do dialysis patients want their advance directives followed? JAMA 1992; 267:59-63

18. Givelber DJ, Bowers WJ, Blitch CL: Tarasoff, myth and reality: an empirical study of private law in action. Wis Law Review $1984 ; 84: 443-497$

19. Wiley $\mathrm{J}$ : The impact of judicial decisions on professional conduct: an empirical study. S Calif Law Review 1981; 55:345-396

20. Fins J: The Patient Self-Determination Act and patientphysician collaboration in New York State. N Y State J Med 1992 ; $92: 489-493$ 